\title{
A Multilevel Model Approach for Assessing the Effects of House and Neighborhood Characteristics on Housing Vacancy: A Case of Daegu, South Korea
}

\author{
Jeong-Il Park \\ Department of Urban Planning, Keimyung University, 1095 Dalgubeol-daero, Dalseo-gu, Daegu 42601, Korea; \\ jip@kmu.ac.kr; Tel.: +82-53-580-5564 \\ Received: 26 March 2019; Accepted: 29 April 2019; Published: 30 April 2019

\begin{abstract}
Previous studies on housing vacancy mostly focused on variables representing regional characteristics while overlooking the characteristics of individual houses. This is due to the limitations of available data. Using the house-level Housing Vacancy Database, this study aims to identify the spatial clustering pattern of vacant houses by examining single-family houses in Daegu, South Korea, and analyze the factors affecting housing vacancy. The Housing Vacancy Database built in this study provides accurate location information of vacant houses, making it possible to analyze the clustering pattern of vacant houses in a more detailed spatial unit. Furthermore, the Housing Vacancy Database considered various physical and neighborhood factors at the house level. The result of hot spot analysis showed that vacant houses were spatially concentrated in the city center. As a result of analyzing the factors affecting housing vacancy at the house level and neighborhood level using a multilevel model, it was found that the physical environment characteristics of individual houses were key factors affecting housing vacancy. Additionally, the probability of housing vacancy tended to increase when the land prices were higher, the houses were located in redevelopment zones, and there were more neighboring vacant houses nearby. Meanwhile, population decline and the ratio of old houses were the only significant variables at the neighborhood level. Thus, this study addresses that policies are needed to improve housing and physical environment characteristics that contribute to housing vacancy.
\end{abstract}

Keywords: housing vacancy; housing abandonment; shrinking cities; house and neighborhood characteristics; Housing Vacancy Database; multilevel model; Korea

\section{Introduction}

Recently, housing vacancy has emerged as a major urban issue in South Korea along with urban shrinkage. According to the 2015 Population and Housing Census, the number of vacant houses in South Korea exceeded 1 million, which accounts for $6.5 \%$ of all houses [1]. Vacant housing may spoil urban aesthetics, destroy neighborhood housing conditions, and increase the risk of fire or crime [2-6]. Deterioration of the neighborhood environment due to housing vacancy leads to the decline of housing satisfaction and prices, resulting in population outflow and additional vacant houses [7]. Ignoring housing vacancy may destroy the community and accelerate urban shrinkage in the long run $[7,8]$.

To develop measures to address housing vacancy, it is necessary to determine where it occurs the most and what factors cause its occurrence. In particular, vacant houses are likely to be clustered in specific areas rather than randomly distributed [2,9-12], and thus it is important to first determine the spatial clustering pattern of vacant houses. Furthermore, accurately diagnosing the factors that cause housing vacancy provides important information for developing suitable policy alternatives. 
Factors that cause housing vacancy may be, at the macroscopic level, population decline and neglected real estate found in shrinking cities due to low birth rates and an aging population [13,14], deindustrialization [14-16], urban sprawl or suburbanization [13,17,18], and natural disasters [14,19]. At the microscopic level, housing vacancy is related to housing market conditions of the region, socioeconomic status, and physical environment characteristics. For example, studies that empirically analyzed the factors of housing vacancy claimed that vacant housing increases in areas where there is population decline or where there is a high ratio of elderly residents or low-income families. Those studies also found that it is likely to occur in areas where dilapidated dwellings, arson, and other crimes are concentrated.

Previous studies on housing vacancy mostly focused on variables representing regional characteristics such as population, unemployment rates, ratio of low-income groups, and frequency of crimes, while overlooking the characteristics of individual houses. Indeed, most case studies use data collected at the level of administrative districts, as it is difficult to obtain data presenting the physical conditions of individual houses and neighborhood built environments.

Recently, in a study on factors causing housing vacancy in Daegu, South Korea, Park and Oh [20] created an individual-level building database. This data not only shows the actual location of vacant housing but also includes variables representing individual building characteristics such as floor area, number of floors, building age, structure, and housing type. Furthermore, it also includes socioeconomic variables at the neighborhood level such as population change, population by age, change in number of establishments, and ratio of low-income groups in analyzing the factors causing housing vacancy. Their study is significant as it considered building-level variables that had been overlooked by other studies on housing vacancy, but its limitation is that the characteristics of the hierarchical data structure are not reflected in terms of research method. Furthermore, the building-level variables considered in their study are strictly limited, and thus it is necessary to consider more diverse individual building-level characteristics such as land price, lot shape, slope, and street interface as potential factors affecting housing vacancy.

This study aims to identify the spatial clustering pattern of vacant houses by examining single-family houses in Daegu, South Korea, and analyze the factors affecting housing vacancy. This study used Daegu Metropolitan City's Vacant Building Database, which was also used by Park and Oh [20]. The data provide accurate locations of vacant houses, making it possible to determine the clustering pattern of vacant houses in a more detailed and elaborate spatial unit. A multilevel model was used to analyze the factors causing housing vacancy, which is suitable for dealing with variables with a nested or hierarchical structure divided at the house and neighborhood level.

\section{Causes of Housing Vacancy}

The occurrence of housing vacancy can be regarded as a phenomenon of a shrinking city at the macroscopic level. Studies on urban shrinkage claimed that low birth rates and an aging population [13,14], deindustrialization [14-16], sprawl or suburbanization $[13,17,18]$, and natural disasters $[14,19]$ cause urban shrinkage, which leads to a long-term decrease of the local population and neglected real estate represented by vacant housing and idle land $[13,17,21]$.

At the microscopic level, the occurrence of housing vacancy is related to the housing market conditions, socioeconomic status, and physical environment characteristics of the region. To begin with, housing market conditions are associated with factors affecting housing demand or supply curves of the region. The most general factor that leads to a decrease in housing demand is population decline. For housing markets, the population change in a specific region can be regarded as the change in housing demand. In regions where the population declines, there is a decrease in housing demand, which may lead to a decrease in housing prices as well as an increase in housing vacancy [22]. The correlation between population decline and the increase of vacant houses has been demonstrated by many studies [20,22-26]. Furthermore, in terms of population structure, housing vacancy may increase in areas where there are many elderly residents $[22,27,28]$. The young generation tends to 
avoid moving to a neighborhood where the elderly population is concentrated, and thus in these neighborhoods, it is likely that housing demand will decrease and housing vacancy will increase [22].

In terms of supply, immoderate housing supply that exceeds housing demand of the region may result in many vacant houses. A study in South Korea found that vacant housing increases in regions where there are many construction permits or a large supply of new houses $[26,28]$. However, since new housing supply usually occurs in regions with a sound housing market and latent demand rather than in declining regions [29], the increase in vacant housing due to an excessive supply of new housing may be a temporary phenomenon such as housing that has not yet been sold or where the residents have not moved in.

Land price is also an important factor of housing market conditions. Low land price is an indicator that represents regional decline or an increase in vacant housing [30]. Moreover, low land prices may keep homeowners from investing in housing repairs, and houses that are not properly maintained become obsolete and end up being vacant [31]. Regions where there is more housing demand than supply are popular regions where many people want to live. Housing prices in these regions are likely to increase, but there is little likelihood of housing vacancy because demand is high [21].

In terms of socioeconomic factors, the proportion of low-income families as well as the racial/ethnic composition of a region serves as key factors impacting housing vacancy. Low-income families face difficulty in purchasing houses or affording high rents, and low-income homeowners may encounter challenges in covering the maintenance costs for their houses or paying property taxes [21,22]. Thus, many studies have shown that vacant housing tends to increase in regions with a high percentage of low-income families [22,32,33]. Furthermore, the racial and ethnic composition of the region is also related to housing vacancy. Case studies in the United States showed an increase in vacant housing in regions with a high percentage of non-white people [32,33].

In terms of physical environment characteristics, housing age, crime, arson, demolitions, or urban redevelopment are related to housing vacancy. Housing age is the most typical factor that reflects the physical environment characteristics. Most studies demonstrated a significant correlation between the ratio of dilapidated dwellings and an increase in vacant housing $[20,26]$. Old houses are physically deteriorated and thus may require greater maintenance costs [34]. If older houses are not properly maintained, they are likely to be avoided by buyers or tenants, thereby becoming vacant houses [21].

Some studies also discovered an increase in vacant housing in regions with a high frequency of crime or arson $[7,22]$. A neighborhood where crime or arson occurs frequently provides the impression that the neighborhood is not a desirable place to live to potential buyers or tenants, which may result in additional neglect and physical decline [21].

House demolitions or urban redevelopment may also cause housing vacancy. However, house demolitions may not have a great influence on increasing vacant housing because it is dispersed and carried out individually, thereby not affecting an entire region [21]. However, urban redevelopment that is planned and carried out intensively produces different outcomes. In a case study in South Korea, Kim et al. [35] determined that an urban redevelopment zone is a significant variable that increases vacant housing.

Previous studies that analyzed the factors affecting housing vacancy mostly focused on regional-level characteristics while overlooking individual house-level characteristics. This is due to the limitations of available data. In particular, most studies related to housing vacancy in South Korea used the Population and Housing Census data $[26,28]$. The data are collected at the level of administrative districts and thus are limited in terms of considering individual house-level characteristics. Recent qualitative studies in South Korea argue that house and neighborhood characteristics are important factors of housing vacancy [9,10]. For example, Jeon and Kim [10] claimed that a poor physical environment such as closed blocks, narrow streets, and small lots are key factors that cause housing vacancy, and this may increase vacant housing in association with the socioeconomic conditions of the region. 
Meanwhile, there have been recent attempts to consider the physical environment characteristics unique to individual buildings or neighborhood housing conditions using data the house level. For example, Park and Oh [20] used the individual-level building database and discovered that attributes of individual buildings such as area, number of floors, and building age have significant effects on the probability of housing vacancy. However, their research methodology failed to reflect the nested data structure, which results from houses being located in a single neighborhood. In other words, these house-level variables have a nested structure at the neighborhood level [36], and thus it is necessary to use a multilevel model for analysis [37].

\section{Data and Methods}

\subsection{Study Area}

This study examines the case of Daegu in South Korea. Daegu is a major metropolitan city that is one of the three largest cities in South Korea, along with Seoul and Busan. The population of Daegu reached its peak in 2010 at 2.512 million and has since declined constantly, reaching a population of 2.485 million in 2016. The population decline in this city is mainly caused by low birth rates-a severe social issue in South Korea-as well as population outflow [38]. In particular, there is almost no natural population growth by birth in the city center, while there is massive population outflow to the outskirts or other cities, thereby resulting in rapid urban decline [38]. Daegu was the leader of economic development and modernization in South Korea based on the textile industry in the 1970-1980s, but it is now facing continuous economic depression as the textile industry declined and the city suffered from a financial crisis. The stagnation of the industrial foundation in the city is causing a decline of residential areas, along with industrial areas formed around the city.

\subsection{Housing Vacancy Database}

Most studies on housing vacancy in South Korea have used housing vacancy data provided by the Population and Housing Census. Because this data is collected at the level of cities, counties, and boroughs, these studies do not consider individual house-level characteristics. This study used the Vacant Building Database used by Park and Oh [20]. The Vacant Building Database is provided by Daegu and has spatial data that can be used to determine the locations of vacant buildings in the entire city as of 2016. Vacant buildings include buildings of all uses such as houses (single- and multi-family houses), retail stores, factories, and warehouses, and it was found that there were 2731 vacant buildings in 2016. This study limited the scope of research to only single-family houses. Buildings of other uses such as apartment buildings, retail stores, factories, and warehouses were excluded because they account for a very small portion, only $0.21 \%$, of all vacant buildings. In particular, even though there are multiple houses in a single apartment building, it is difficult to reflect this because of limited data.

The Vacant Building Database has only spatial information of vacant buildings and thus must be combined with separate data on housing locations and other attributes. This study established the individual house-level Housing Vacancy Database through data processing as shown in Figure 1. To do so, first, the GIS Integrated Building Database and Vacant Building Database were combined. The GIS Integrated Building Database is spatial data that can determine the location and form of all buildings and contains attribute data such as use, number of floors, year of construction, structure, etc. The two databases were combined using spatial analysis and Parcel Numbering Unit (PNU) codes. Then, this was combined with the Building Register-which additionally provides individual house-level variables such as lot shape, slope, street, land price, etc.- - using PNU codes as a non-spatial database. Next, single-family houses were extracted using the attribute data of building use. As a result, 143,460 single-family houses were extracted within the study area. Moreover, the number of vacant houses within $500 \mathrm{~m}$ of individual houses was also calculated through spatial analysis. Finally, neighborhood-level variables were added in combination with the Population and Housing Census and National Establishment Survey. 


\section{Data Processing}

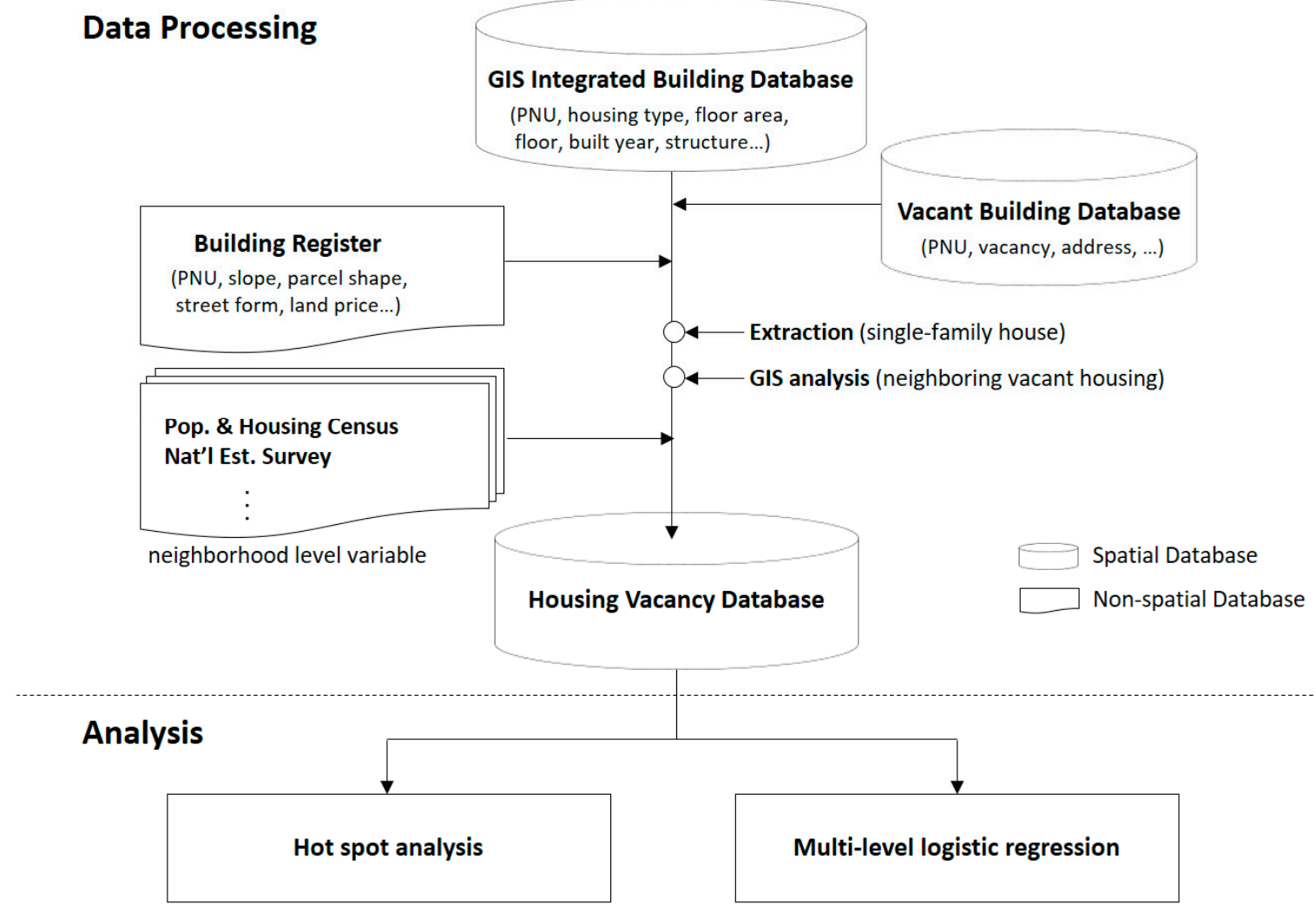

Figure 1. Data processing and analysis.

\subsection{Methods}

This study conducted a hot spot analysis to determine the spatial clustering pattern of vacant single-family houses in Daegu. Hot spot analysis is used to determine whether a certain event is spatially concentrated in specific areas [39]. Whether there is vacant housing was established as the weight in the hot spot analysis based on the pointer data that represents housing location. The fixed distance band was used for spatial relation, and the critical distance was set as $500 \mathrm{~m}$. This is based on the method of analysis used by Han and Lee [40], who analyzed the spatial distribution characteristics of vacant housing considering that walking distance is generally within $500 \mathrm{~m}$. Hot spot analysis calculates Getis-Ord Gi* statistics of each individual house, which was the analysis unit. Hot spots are where other vacant houses are clustered near vacant houses, and cold spots are where other non-vacant houses are clustered near non-vacant houses.

To analyze factors affecting housing vacancy, this study used a multilevel model. A multilevel model is an analytical tool that is suitable for cases in which low-level (e.g., individual, establishment, house) variables have a nested or hierarchical structure at a higher level (e.g., group, region) [37,41]. A multilevel logistic regression model was used considering that the dependent variables are binomial variables divided into vacant housing and non-vacant housing. Stata/MP 15 software was used in this analysis.

In the multilevel model, the independent variables were classified into house (low level) and neighborhood (high level). The house-level independent variables include physical environment characteristics of housing, such as area, number of floors, housing age, and structure, which were considered in the analysis by Park and Oh [20]. Variables that represent individual house characteristics were also added to this study, such as land price, lot shape, slope, and street.

Vacant houses are likely to be clustered in specific areas rather than being randomly distributed. In particular, many studies have found that the occurrence of housing vacancy has a high spatial correlation with housing vacancy in neighboring areas [2,9-12]. For statistical verification, this study 
calculated the number of vacant houses within $500 \mathrm{~m}$ of individual buildings through spatial analysis and included that in the variables.

For the neighborhood level, eup-myeon-dong, which is the lowest level of administrative districts in South Korea, was used as the unit. Variables representing neighborhood characteristics included various socioeconomic characteristics based on the literature review: demographic characteristics of the neighborhood such as population change in the last 5 years, elderly-child ratio, percentage of foreign households, and percentage of national basic livelihood security recipients, as well as economic characteristics such as employment growth in all industries and in manufacturing. Moreover, the ratio of old dwellings that are at least 30 years old, the ratio of new houses built in the last 5 years, and redevelopment zone areas were also included as variables. Table 1 shows the descriptive statistics for each variable. 
Table 1. Descriptive statistics.

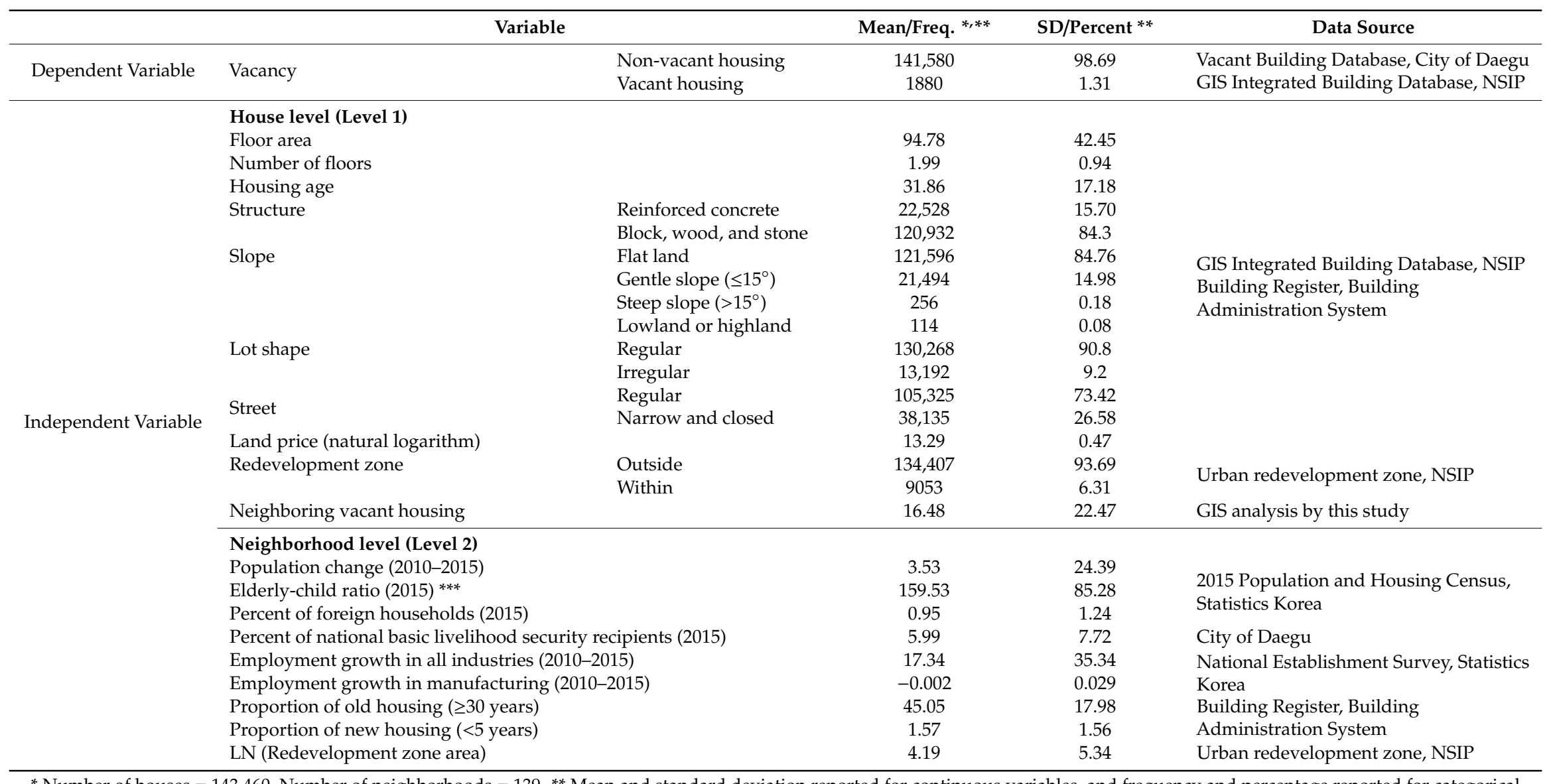

$*$ Number of houses $=143,460$, Number of neighborhoods $=139 . * *$ Mean and standard deviation reported for continuous variables, and frequency and percentage reported for categorical variables. ${ }^{* * *}$ Elderly-child ratio $=($ Population aged 65 and over/Population aged $0-14) \times 100 ;$ NSIP: National Spatial Information Portal. 


\section{Results and Discussion}

\subsection{Spatial Clustering Pattern of Vacant Housing}

The spatial clustering pattern of vacant housing that appeared through hot spot analysis is shown in Figure 2. The hot spots of vacant housing in red were concentrated in the heart of the city. One unusual characteristic is that the hot spots of vacant housing produced a doughnut-shaped pattern with a void in the central business district. This void is related not only to the concentration of business and commercial buildings in this area, but also to the massive supply of new apartment buildings that emerged in the city center due to redevelopment [20,42]. On the other hand, cold spots in blue surrounded the hot spots, which reflect a concentration of large-scale apartment complexes developed after the 1990s. The single-family houses around them were also not vacant. Vacant houses in Daegu were clustered near old residential areas around the city center, and non-vacant houses were clustered in the new housing complexes on the outskirts developed after the 1990s. Previous studies explain that there are two reasons for this clustering pattern of vacant houses. One reason is because houses in certain spaces were built around the same time and are of a similar type and style [12]. The other is because spatial clustering of vacant houses may originate from different socioeconomic characteristics of neighborhoods, such as income, race, education level, and occupation [12,43,44]. The results of hot spot analysis in this study suggest that similarity in physical environment characteristics such as year of construction and building style has a greater effect on the clustering pattern of vacant houses than socioeconomic characteristics.

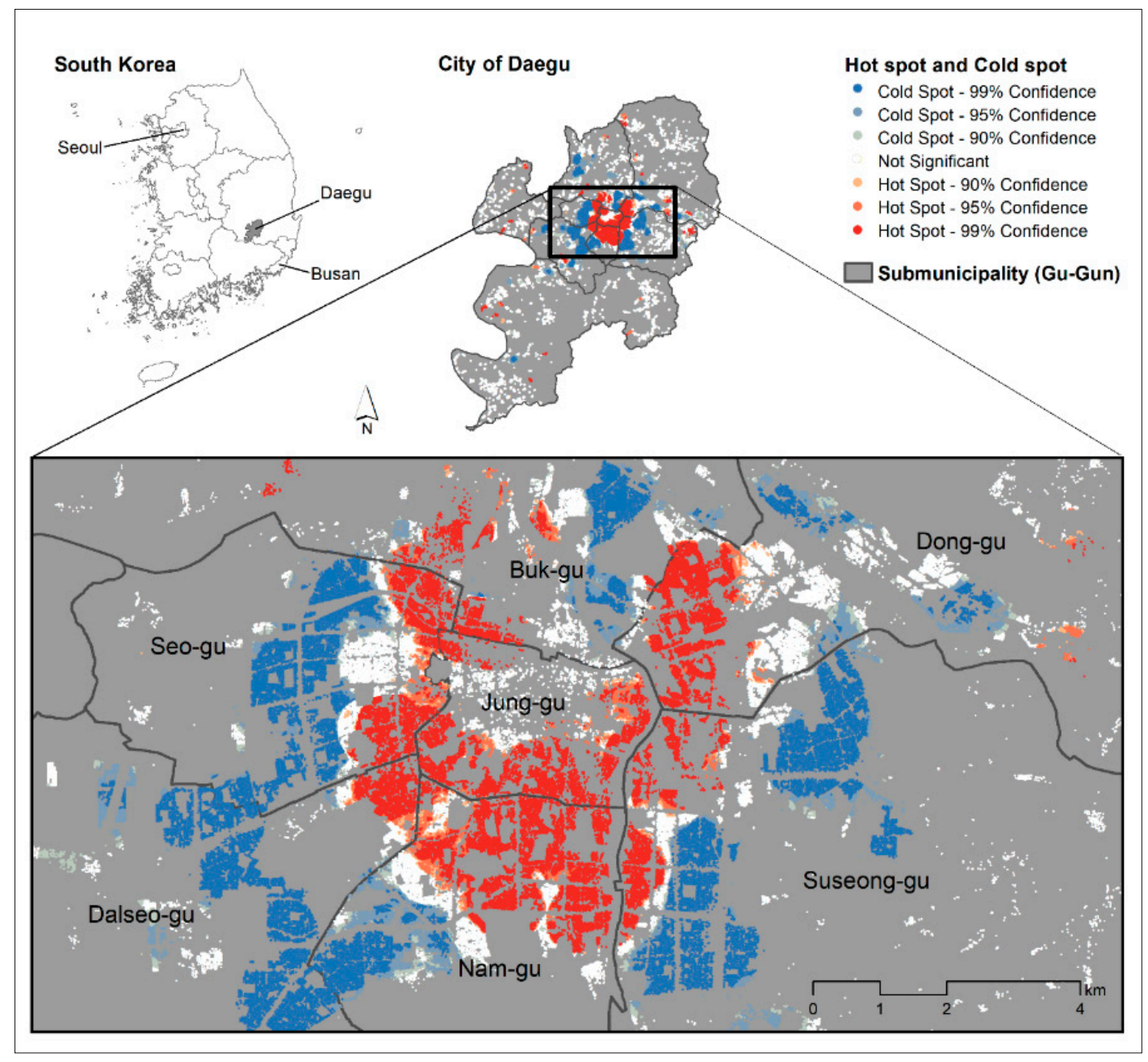

Figure 2. Hot spots and cold spots of vacant housing in Daegu, Korea. 


\subsection{Factors Affecting Housing Vacancy}

Table 2 shows the results of the multilevel model that analyzed the house-level and neighborhood-level factors affecting housing vacancy. Model 1 was an unconditional model that did not include independent variables, but rather calculated the explanatory power of the probability of housing vacancy from the variance data of the house level (Level 1) and neighborhood level (Level 2) before the independent variables were included. It was possible to determine the intra-class correlation (ICC), which is the variance ratio explained by the difference in the neighborhood level, among the house-level variance, neighborhood-level variance, and total variance of housing vacancy that affected the probability of housing vacancy [37]. The ICC calculated in Model 1 was 0.345 , which indicates that the probability was explained by the difference in the neighborhood level by $34.5 \%$. Meanwhile, Model 2 included only house-level variables. The ICC of Model 2 was 0.115 , which was remarkably lower than that of Model 1. The ICC of Model 3, which included both house-level and neighborhood-level variables, was 0.101 .

Table 2. Summary of model building, model comparison, and model fit.

\begin{tabular}{cccc}
\hline Model & ICC & AIC & BIC \\
\hline Model 1: Unconditional model & 0.345 & $18,340.07$ & $18,359.81$ \\
Model 2: House-level variables only & 0.115 & $16,111.93$ & $16,250.17$ \\
$\begin{array}{c}\text { Model 3: Both house- and } \\
\text { neighborhood-level variables }\end{array}$ & 0.101 & $16,111.84$ & $16,341.93$ \\
\hline
\end{tabular}

The fit of the multilevel model can be compared using Akaike Information Criterion (AIC) and Schwarz's Bayesian Information Criterion (BIC) [37,41]. In general, lower AIC and BIC values indicate a better model. The AIC values calculated in each model of Table 2 gradually decreased: 18,340.07 in Model 1, 16,111.93 in Model 2, and 16,111.84 in Model 3. The BIC value is lowest for the Model 2 $(16,250.17)$, but only slightly lower than for Model $3(16,341.93)$. Thus, this study adopted Model 3 , which included both house-level and neighborhood-level independent variables, as the final model. Thus, the results of Model 3 will be discussed below.

Table 3 shows the results of the multilevel logistic regression analyzing factors that affect housing vacancy. The dependent variables in this model are binomial variables divided into vacant and non-vacant housing. Both house-level and neighborhood-level variables were included as independent variables. In sum, while most regression coefficients of house-level variables were statistically significant, only population change and the ratio of old housing were significant at the neighborhood level. A deeper discussion of the factors that affect housing vacancy follows.

First, physical environment characteristics of housing affected housing vacancy at the house level. Variables that represent physical environment characteristics of housing such as floor area, number of floors, housing age, building structure, slope, lot shape, and street were all statistically significant. Floor area and the number of floors were significantly and negatively correlated with housing vacancy, which indicates that houses with a small floor area and number of floors were more likely to be vacant. Housing age had a significant and positive coefficient, which indicates that older houses were more likely to be vacant. Housing structure was also a significant factor. The regression coefficients of block, wood, and stone were also positive and statistically significant. This indicates that block, wood, and stone houses, which are structurally weaker than reinforced concrete houses, were more likely to be vacant.

The physical environment characteristics of lots where the houses were located were also important. The regression coefficient of slope showed that houses located on a gentle slope (15 degrees or less) or on lowland and highland were more likely to be vacant than houses on flatland. As for lot shape, houses on irregularly shaped lots were more likely to be vacant than regularly shaped lots. Moreover, houses that face narrow or closed streets were more likely to be vacant. These results are similar to previous studies that found that areas with a higher ratio of small houses $[10,45]$ or old houses $[20,26]$ 
have a higher probability of housing vacancy. However, while these studies examined the physical environment at the regional level, this study demonstrated that the physical environment at the house level was a factor that significantly affects housing vacancy.

Table 3. Multilevel binomial regression results for housing vacancy.

\begin{tabular}{|c|c|c|c|}
\hline & & Coef. & $\mathbf{t}$ \\
\hline \multicolumn{4}{|l|}{ House level (Level 1) } \\
\hline \multicolumn{2}{|l|}{ Floor area } & $-0.0132^{* * *}$ & $(-13.8422)$ \\
\hline \multicolumn{2}{|l|}{ Number of floors } & $-1.0979^{* * *}$ & $(-18.0910)$ \\
\hline \multicolumn{2}{|l|}{ Housing age } & $0.0105^{* * *}$ & $(7.5937)$ \\
\hline \multirow{2}{*}{ Structure } & Reinforced concrete & (ref.) & \\
\hline & $\begin{array}{l}\text { Block, wood, and stone } \\
\text { Flat land }\end{array}$ & $\begin{array}{l}-0.3137 * \\
\text { (ref.) }\end{array}$ & $(-1.6537)$ \\
\hline \multirow{3}{*}{ Slope } & Gentle slope & $0.2142^{* * *}$ & $(3.1662)$ \\
\hline & Steep slope & -0.4994 & $(-0.6871)$ \\
\hline & Lowland or highland & $0.9370^{* * *}$ & $(2.6290)$ \\
\hline \multirow{2}{*}{ Lot shape } & Regular & (ref.) & \\
\hline & Irregular & $0.1707^{* *}$ & $(2.5054)$ \\
\hline \multirow{2}{*}{ Street } & Regular & (ref.) & \\
\hline & Narrow and closed & $0.4854^{* * *}$ & $(8.2020)$ \\
\hline \multicolumn{2}{|l|}{ LN (Land price) } & $0.1733 *$ & $(1.9021)$ \\
\hline \multirow{2}{*}{ Redevelopment zone } & Outside & (ref.) & \\
\hline & Within & $0.3653^{* * *}$ & $(4.8492)$ \\
\hline \multicolumn{2}{|c|}{ Neighboring vacant housing } & $0.0196^{* * *}$ & $(13.3895)$ \\
\hline \multicolumn{4}{|c|}{ Neighborhood level (Level 2) } \\
\hline \multicolumn{2}{|l|}{ Population change } & $-0.0111^{* * *}$ & $(-2.7243)$ \\
\hline \multicolumn{2}{|l|}{ Elderly-child ratio } & -0.0017 & $(-1.3885)$ \\
\hline \multicolumn{2}{|c|}{ Percent of foreign households } & 0.0046 & $(0.3400)$ \\
\hline \multicolumn{2}{|c|}{ Percent of national basic livelihood security recipients } & 0.0813 & $(1.3762)$ \\
\hline \multicolumn{2}{|c|}{ Employment growth in all industries } & 0.0016 & $(0.9651)$ \\
\hline \multicolumn{2}{|c|}{ Employment growth in manufacturing } & 2.3525 & $(0.8923)$ \\
\hline \multicolumn{2}{|c|}{ Proportion of old housing } & $0.0081 *$ & $(1.6659)$ \\
\hline \multicolumn{2}{|c|}{ Proportion of new housing } & 0.0506 & $(1.1880)$ \\
\hline \multicolumn{2}{|c|}{ LN (Redevelopment zone area) } & 0.0155 & $(1.2038)$ \\
\hline \multicolumn{2}{|l|}{ Cons } & $-5.9825 * * *$ & $(-4.7965)$ \\
\hline \multicolumn{4}{|l|}{ Model Summary } \\
\hline \multicolumn{2}{|c|}{ Number of observations } & 143,460 & \\
\hline \multicolumn{2}{|c|}{ Number of groups } & 139 & \\
\hline \multicolumn{2}{|l|}{ ICC } & 0.100759 & \\
\hline \multicolumn{2}{|l|}{ AIC } & $16,111.84$ & \\
\hline \multicolumn{2}{|l|}{$\mathrm{BIC}$} & $16,341.93$ & \\
\hline
\end{tabular}

${ }^{*} p<0.1,{ }^{* *} p<0.05,{ }^{* * *} p<0.01$

Second, land price had a positive coefficient with statistical significance, which indicates that houses with higher land prices were likely to be vacant. This is contrary to the results of previous research claiming that higher land prices lead to a lower probability of housing vacancy [30]. It is also inconsistent with the explanation that, since high land prices reflect high housing demand, houses are less likely to be neglected and vacant [21]. This result can be interpreted as follows. As shown in Figure 2, vacant houses in Daegu were clustered in the city center where land prices were relatively high. These vacant houses likely remained vacant by suppressing housing demand.

Third, houses in redevelopment zones were more likely to be vacant. Redevelopment zones are designated by local governments to methodically recover urban functions, redevelop areas with a poor residential environment, and promote efficient improvement of old and deteriorated buildings. The results of this analysis showed that there was a statistically significant positive correlation between 
redevelopment zones and housing vacancy, which indicates that houses located within redevelopment zones were more likely to be vacant than houses outside of such zones. Places that are designated as redevelopment zones and are undergoing redevelopment and reconstruction may cause housing vacancy while the project is being carried out; however, in such areas, there are also many cases in which vacant houses are left abandoned for a long period because there is a delay in the implementation of the project even after being designated as a redevelopment zone [46].

Fourth, neighboring vacant houses also impacted housing vacancy. As shown in the hot spot analysis results in Figure 2, vacant houses were clustered together in specific areas. In the multilevel model analysis results, the regression coefficient of neighboring vacant housing was positive and statistically significant. This indicates that the more vacant houses there were within $500 \mathrm{~m}$ of each house, the more likely that the houses were vacant. In other words, if there is one vacant house in a region, the houses around it will be affected and are more likely to become vacant.

Finally, population change and the ratio of old housing were the only variables affecting housing vacancy at the neighborhood level. Population change had a significant and negative coefficient, which indicates that housing vacancy was likely to occur in areas where the population growth had been low over the last 5 years. The population change in Daegu showed a contrast between a population decline in the city center and a population increase in the outskirts of the city. This is related to the constant outflow of the city population to the outskirts [38]. As shown in Figure 2, vacant houses were concentrated in the city center, which implies that housing vacancy in the city center was caused by population decline due to the outflow of population. Moreover, the ratio of old houses had a significant and positive coefficient, which indicates that houses were more likely to be vacant if they were located in a neighborhood where a high ratio of houses were constructed at least 30 years ago.

\section{Conclusions}

This study aimed to identify the spatial clustering pattern of vacant houses in a city and analyze the factors affecting housing vacancy at the house level and neighborhood level. To this end, the house-level Housing Vacancy Database was used in this analysis. While previous studies focused only on regional-level variables using data from the Population and Housing Census, the house-level Housing Vacancy Database built in this study includes various physical and neighborhood factors at the house level, such as location of vacant housing, floor area, number of floors, year of construction, building structure (material), land price, lot shape, slope, street, etc. Furthermore, the Housing Vacancy Database also provides accurate location information of vacant houses, making it possible to analyze the clustering pattern of vacant houses in a more detailed spatial unit.

The results of analyzing the spatial clustering pattern of vacant houses through the hot spot analysis showed that the hot spots were concentrated in the city center with a void in the central business district. By contrast, the cold spots were concentrated in the boundary areas of the center where large-scale apartment complexes were clustered.

As a result of analyzing the factors affecting housing vacancy at the house level and neighborhood level using a multilevel model, it was found that the unique characteristics of individual houses were factors that had significant effects on housing vacancy. Smaller houses, houses with fewer floors, older houses, and houses built with block/wood/stone were more likely to be vacant. Houses located on a gentle slope (15 degrees or lower) or highland and lowland, lots in irregular shapes, and houses adjacent to narrow or closed streets were also likely to be vacant. These results show that physical environment characteristics of individual houses are key factors affecting housing vacancy. Furthermore, the probability of housing vacancy tended to increase when land prices were higher, houses were located in redevelopment zones, and there were more neighboring vacant houses nearby. Meanwhile, population decline and the ratio of old houses were the only significant variables at the neighborhood level.

The results of this study showed that it is important to improve the physical environment of individual houses to manage housing vacancy at the microscopic level. Houses that are small, old, and 
not structurally strong and poor physical environments with closed blocks, narrow streets, and slopes are key factors that cause housing vacancy. Thus, policies are needed to improve such housing and physical environment characteristics. Vacant housing may lead to more vacant housing in neighboring areas, which is why it is necessary to develop measures for areas where vacant houses are clustered. In particular, since vacant houses are clustered in the city center of Daegu as determined in this study, it is necessary to first establish measures for the residential areas of the city center that are not in a physically favorable condition.

Funding: This research was supported by the Keimyung University research grant of 2016.

Conflicts of Interest: The author declares no conflict of interest.

\section{References}

1. Statistics Korea. 2015 Popluation and Housing Census (Whole Sector): Aggregation Results for Registered Census; Statistics Korea: Daejeon, Korea, 2016.

2. Son, E.J.; Maeng, H.Y.; Lee, H.Y. The spatio-temporal patterns of the vacant homes clusters and their impact on the neighborhood land price: The case of Busan Metropolitan City. J. Real Estate Anal. 2015, 1, 71-90. [CrossRef]

3. You, J.S.; Lee, D.Y. Classification of the vacant housing type based on the physical condition and hazard level of vacant houses. J. Korean Urban Geogr. Soc. 2017, 20, 1-13. [CrossRef]

4. Cohen, J.R. Abandoned housing: Exploring lessons from Baltimore. Hous. Policy Debate 2001, 12, 415-448. [CrossRef]

5. Han, H.-S. The impact of abandoned properties on nearby property values. Hous. Policy Debate 2014, 24, 311-334. [CrossRef]

6. Immergluck, D.; Smith, G. The impact of single-family mortgage foreclosures on neighborhood crime. Hous. Stud. 2006, 21, 851-866. [CrossRef]

7. Schilling, J.M. The Revitalization of Vacant Properties: Where Broken Windows Meet Smart Growth; International City/County Management Association: Washington, DC, USA, 2002.

8. Kim, J.H.; Nam, J. A study on vacant house distribution and management of urban declining area. J. KRSA 2016, 32, 105-122.

9. Kwon, H.-S.; Kim, H.-J; Yoon, J.-J.; Park, J.-K.; Kim, H.-S.; Park, H.-G. Current status of vacant housing and those utilization: Revitlization strategy for low-rise residentail area. Urban Inf. 2017, 12, 4-18.

10. Jeon, Y.; Kim, S. The causes and characteristics of housing abandonment in an inner-city neighborhood: Focused on the Sungui-dong area, Nam-gu, Incheon. Urban Des. 2016, 17, 83-100.

11. Han, S.K.; Lee, H.Y. Analysis of neighborhood characteristics for the reuse of vacant houses. J. Korean Urban Geogr. Soc. 2017, 20, 15-27. [CrossRef]

12. Morckel, V.C. Spatial characteristics of housing abandonment. Appl. Geogr. 2014, 48, 8-16. [CrossRef]

13. Koo, H.; Kim, T.; Lee, S. Urban Shrinkage in Korea: Current Status and Policy Implications; Korea Research Institute for Human Settlement: Anyang, Korea, 2016.

14. Pallagst, K.; Wiechmann, T.; Martinez-Fernandez, C. Shrinking Cities: International Perspectives and Policy Implications; Routledge: New York, NY, USA, 2013.

15. Hollander, J.B.; Pallagst, K.; Schwarz, T.; Popper, F.J. Planning shrinking cities. Prog. Plan. 2009, 72, 223-232.

16. McDonald, K.I. Urban America: Growth, Crisis, and Rebirth: Growth, Crisis, and Rebirth; M.E. Sharpe: Armonk, NY, USA, 2008.

17. Lee, H.Y.; Han, S.K. Stray Shrinking Cities, Where to Go; Korea Research Institute of Human Settlement: Anyang, Korea, 2014.

18. Martinez-Fernandez, C.; Audirac, I.; Fol, S.; Cunningham-Sabot, E. Shrinking cities: Urban challenges of globalization. Int. J. Urban Reg. Res. 2012, 36, 213-225. [CrossRef]

19. Vale, L.J.; Campanella, T.J. The Resilient City: How Modern Cities Recover from Disaster; Oxford University Press: New York, NY, USA, 2005.

20. Park, J.-I.; Oh, S.-K. Spatial pattern and causative factor analysis of vacant housing in Daegu, South Korea using individual-level building DB. J. Korean Reg. Sci. Assoc. 2018, 34, 35-47. 
21. Morckel, V.C. Empty neighborhoods: Using constructs to predict the probability of housing abandonment. Hous. Policy Debate 2013, 23, 469-496. [CrossRef]

22. Mallach, A. Bringing Buildings Back: From Abandoned Properties to Community Assets: A Guidebook for Policymakers and Practitioners; Rutgers University Press: New Brunswick, NJ, USA, 2006.

23. Mallach, A. Facing the Urban Challenge: The Federal Government and America's Older Distressed Cities; Metropolitan Policy Program at Brookings: Washington, DC, USA, 2010.

24. Mallach, A.; Brachman, L. Ohio's Cities at a Turning Point: Finding the Way Forward; Metropolitan Policy Program at Brookings: Washington, DC, USA, 2010.

25. Nassauer, J.I.; Raskin, J. Urban vacancy and land use legacies: A frontier for urban ecological research, design, and planning. Landsc. Urban Plan. 2014, 125, 245-253. [CrossRef]

26. Noh, M.J.; Yoo, S.J. An study on the cause of abandoned vacant houses. Korea Real Estate Rev. 2016, 26, 7-21.

27. Culhane, D.P.; Hillier, A.E. Comment on James R. Cohen's “abandoned housing: Exploring lessons from Baltimore". J. Hous. Debate 2001, 12, 449-455. [CrossRef]

28. Nam, J.; Han, J.; Lee, C. Factors contributing to residential vacancy and some approaches to management in Gyeonggi Province, Korea. Sustainability 2016, 8, 367. [CrossRef]

29. Glaeser, E.L.; Gyourko, J. Urban decline and durable housing. J. Political Econ. 2005, 113, 345-375. [CrossRef]

30. Hillier, A.E.; Culhane, D.P.; Smith, T.E.; Tomlin, C.D. Predicting housing abandonment with the Philadelphia neighborhood information system. J. Urban Aff. 2003, 25, 91-106. [CrossRef]

31. Kim, K.H.; Son, J.Y. Real Estate Economics, 2nd ed.; Konkuk University Press: Seoul, Korea, 2017.

32. Bassett, E.M.; Schweitzer, J.; Panken, S. Understanding Housing Abandonment and Owner Decision-Making in Flint, Michigan: An Exploratory Analysis; Genesee Career Institute: Flint, MI, USA, 2006.

33. Immergluck, D. Examining changes in long-term neighborhood housing vacancy during the 2011 to 2014 US national recovery. J. Urban Aff. 2015, 38, 607-622. [CrossRef]

34. Clark, D.E.; Herrin, W.E. Historical preservation districts and home sale prices: Evidence from the Sacramento housing market. Rev. Reg. Stud. 1997, 27, 29-48.

35. Kim, K.H.; Han, E.J.; Sohn, S.Y. Identifying influential factors to residential vacancy in Seoul based on a geographically weighted lasso model. J. Korean Inst. Ind. Eng. 2018, 44, 54-68.

36. Morckel, V.C. Does the house or neighborhood matter more? Predicting abandoned housing using multilevel models. Cityscape 2015, 17, 61-70.

37. Hox, J.J. Multilevel Analysis: Techniques and Applications, 2nd ed.; Routledge: New York, NY, USA, 2010.

38. Park, J.-I.; Kim, J.-H. A study on the change of population distribution in metropolitan area by the development of the new town-type innovation city: A case study of the Daegu Innovation City in South Korea. J. Korean Reg. Sci. Assoc. 2018, 34, 55-68.

39. Ord, J.K.; Getis, A. Local spatial autocorrelation statistics: Distributional issues and an application. Geogr. Anal. 1995, 27, 286-306. [CrossRef]

40. Han, S.K.; Lee, H.Y. Analysis of the spatial distribution and characteristics of the vacant/abandoned properties: The case of Iksan. J. Korean Urban Geogr. Soc. 2016, 19, 1-16. [CrossRef]

41. Raudenbush, S.W.; Bryk, A.S. Hierarchical Linear Models: Applications and Data Analysis Methods; Sage: Thousand Oaks, CA, USA, 2002.

42. Chang, Y.-H. Daegu Jung-gu, apartment construction boom...transformation to 'residence town'. DongA. 19 December 2014. Available online: http://news.donga.com/3/03/20141210/68451432/1 (accessed on 4 April 2019).

43. Bender, B. The determinants of housing demolition and abandonment. South. Econ. J. 1979, 131-144. [CrossRef]

44. Scafidi, B.P.; Schill, M.H.; Wachter, S.M.; Culhane, D.P. An economic analysis of housing abandonment. J. Hous. Econ. 1998, 7, 287-303. [CrossRef]

45. Lee, J.; Newman, G. Forecasting urban vacancy dynamics in a shrinking city: A land transformation model. ISPRS Int. J. Geo-Inf. 2017, 6, 124.

46. Lee, H.Y.; Lee, Y.S. Development of spatial decision support system for promoting the community-specific reuse of vacant houses. J. Korean Urban Geogr. Soc. 2017, 20, 29-43. [CrossRef]

(C) 2019 by the author. Licensee MDPI, Basel, Switzerland. This article is an open access article distributed under the terms and conditions of the Creative Commons Attribution (CC BY) license (http://creativecommons.org/licenses/by/4.0/). 